\title{
REACTIONS OF POLYCYCLIC ALKYLAROMATICS-VI. DETAILED CHEMICAL KINETIC MODELING
}

\author{
C. MICHAEL SMITH and PHILLIP E. SAVAGE ${ }^{\dagger}$ \\ University of Michigan, Department of Chemical Engineering, Ann Arbor, MI 48109-2136, U.S.A.
}

(First received 26 January 1993; accepted in revised form 12 July 1993)

\begin{abstract}
We developed a detailed chemical kinetics model for the pyrolysis of long-chain polycyclic n-alkylarenes based on a general frec-radical mechanism. The model accounts for the two major primary pathways in the pyrolysis network of polycyclic alkylaromatics. Using 1-dodecylpyrene (DDP) as an example, we show that the model qualitatively predicted the effects of time, temperature, and concentration on the product molar yields and the reaction kinetics. The model also predicted the autocatalytic kinetics associated with the cleavage of the aryl-alkyl bond. The model results showed that radical hydrogen transfer was the dominant hydrogenolysis mechanism during all but the very initial stages of the reaction when reverse radical disproportionation dominated. A sensitivity analysis revealed that reactions involving $\alpha$-DDP radicals were the most important in determining the reaction kinetics and the product sclectivities.
\end{abstract}

\section{INTRODUCTION}

Long-chain $n$-alkylaromatic moieties are important structural elements in heavy hydrocarbon resources such as coals, kerogens, heavy crude oils, and petroleum residua. Further, essentially all conversion and upgrading schemes for these materials involve processes that operate at elevated temperatures where thermal reactions can be important. Thus, a complete understanding of the process chemistry for heavy hydrocarbons can be obtained only after the thermal reaction pathways, kinetics and mechanisms of longchain $n$-alkylaromatics have been fully elucidated.

The pyrolysis of long-chain $n$-alkylbenzenes is well understood (Poutsma, 1990; Mushrush and Hazlett, 1984; Blouri et al., 1985; Savage and Klein, 1987a, b, 1989; Freund and Olmsted, 1989), but the pyrolysis of polycyclic $n$-alkylaromatics has received considerably less attention until very recently (Smith and Savage, 1993, 1992, 1991a-c; Savage et al., 1989; Freund et al., 1991; McMillen et al., 1991, 1992; Virk and Vlastnik, 1992). The feature that distinguishes the pyrolysis of many polycyclic $n$-alkylaromatics from the pyrolysis of their single-ring counterparts is the presence of a major primary pathway that proceeds with autocatalytic kinetics to cleave the aryl-alkyl $\mathrm{C}-\mathrm{C}$ bond. This pathway is intriguing because the aryl-alkyl $\mathrm{C}-\mathrm{C}$ bond is the strongest in the alkyl chain.

Smith and Savage (1991a, c) showed that the relative importance of this hydrogenolysis pathway depends upon the specific structure of the $n$-alkylarene, its concentration, and its conversion. It is the major primary pathway for compounds substituted at positions with low localization energies and for pyrolyses at high concentrations (e.g. liquid phase) and high conversions.

The mechanism responsible for this aryl-alkyl bond cleavage involves the addition of hydrogen to

\footnotetext{
'Author to whom correspondence should be addressed.
}

the ipso position and the subsequent elimination of the alkyl substituent. Potential mechanisms include reverse radical disproportionation (RRD) (Billmers et al., 1986, 1989), radical hydrogen transfer (RHT) (McMillen et al, 1987), and hydrogen atom ipsosubstitution (Vernon, 1980). These hydrogen transfer mechanisms have only recently been proposed and the extent to which each engenders the hydrogenolysis observed in polycyclic $n$-alkylaromatics is not known. Experimental evidence (Smith and Savage, $1991 \mathrm{a}, \mathrm{c})$ suggests that the mechanism is moderately selective, however, which implicates RRD and RHT as likely candidates. The importance of polycyclic $n$-alkylarenes as chemical models for heavy hydrocarbon resources and the lack of knowledge about the governing pyrolysis mechanisms motivated the development of the detailed chemical kinetics model reported herein.

\section{PYROLYSIS MECHANISM}

Figure 1 displays the elementary free-radical steps that describe DDP pyrolysis. Employing standard notation, we use $\mu$ to identify radicals that participate in unimolecular propagation reactions and $\beta$ to identify radicals that react in bimolecular steps. Table 1 provides the chemical identity of each of the species in Fig. 1. This mechanism for DDP is an extension of the long-chain $n$-alkylbenzene pyrolysis mechanism developed by Savage and Klein (1989) and the ethylpyrene pyrolysis mechanism recently developed by Smith and Savage (1992). The key features of the mechanism are outlined in the following paragraphs.

The generation of free radicals occurs in the initiation steps numbered 1-3. In step 1 , initiation occurs through homolytic dissociation of the week bond between the $\alpha$ and $\beta$ carbon atoms in DDP (A) to yield a methylpyrenyl radical $\left(\beta_{1}\right)$ and an undecyl radical $\left(\beta_{3}\right)$. This type of step is the dominant initiation pathway for alkylbenzenes. Steps 2 and 3 depict bimolecular initiation routes through reverse radical disproportionation (RRD). This type of step is the 
Table 1. Identity of species in Fig. 1 for DDP pyrolysis

\begin{tabular}{clll}
\hline Symbol & \multicolumn{1}{c}{ Species } & Symbol & \multicolumn{1}{c}{ Species } \\
\hline$\beta_{1}$ & Methylpyrenyl radical & $\beta_{1} \mathbf{H}$ & Methylpyrene \\
$\beta_{2}$ & $n$-Decyl radical & $\beta_{2} \mathbf{H}$ & Decane \\
$\beta_{3}$ & Other primary radicals & $\beta_{3} \mathbf{H}$ & Alkanes and alkylpyrenes \\
$\beta_{4}$ & $n$-Dodecyl radical & $\beta_{4} \mathbf{H}$ & Dodecane \\
$\beta_{5}$ & Hydrogen atom & $\beta_{3} \mathbf{H}$ & Hydrogen \\
$\mu_{1}$ & $\gamma$-Dodecylpyrene radical & $\mathbf{Q}_{1}$ & 1-Undecene \\
$\mu_{2}$ & $\alpha$-Dodecylpyrene radical & $\mathbf{Q}_{2}$ & Vinylpyrene \\
$\mu_{3}$ & Other 20 DDP radicals & $\mathbf{Q}_{3}$ & Alkenes \& alkenylpyrenes \\
$\mu_{4}$ & Ipso-dodecylhydropyrenyl radical & $\mathbf{Q}_{4}$ & Pyrene \\
$\mu_{5}$ & Non-ipso alkylhydropyrenyl & $\mathbf{R}$ & 1-Pyrene poisition \\
$P_{i}$ & $\alpha$-Olefins & $\mathbf{I}_{i}$ & Internal olefins \\
\hline
\end{tabular}

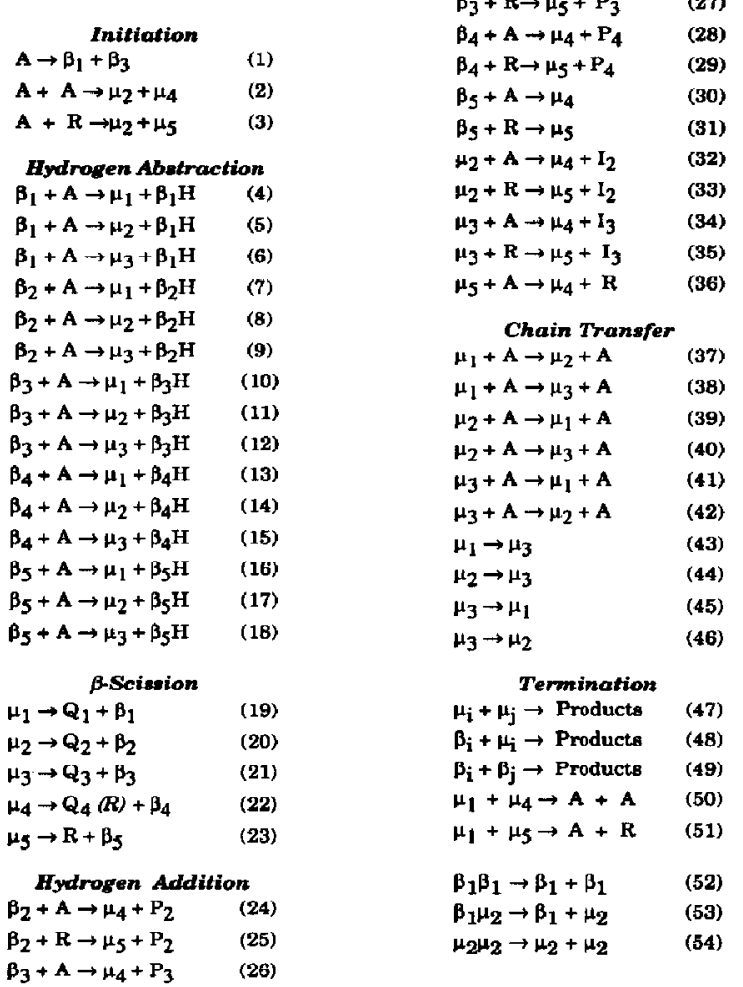

Fig. 1. DDP pyrolysis mechanism.

dominant initiation pathway for polycyclic methylarenes (Smith and Savage, 1992). In step 2, hydrogen is transferred from the $\alpha$-carbon in the alkyl chain in one DDP molecule to the substituted aromatic position on a second DDP molecule to yield an ipsododecylhydropyrenyl radical $\left(\mu_{4}\right)$ and an $\alpha$-DDP radical $\left(\mu_{2}\right)$. RRD steps can also transfer hydrogen to non-ipso positions on DDP and pyrene-containing reaction products such as methylpyrene, ethylpyrene, and pyrene. The 3,6 , and 8 positions in pyrene are the most reactive hydrogen acceptors among the nonipso positions, so these are the most likely to participate in hydrogen transfer steps (Smith and Savage,
1992). The model includes hydrogen transfer by RRD to these non-ipso aromatic positions in the reaction mixture by lumping all of these positions together as one pseudo-reactant, which is denoted as R in Fig. 1. Step 3 shows hydrogen transfer by RRD from the benzylic position in DDP to a non-ipso position ( $R$ ) on a pyrene unit. The result of this reaction is the formation of a $\mu_{2}$ radical and a non-ipso alkylhydropyrenyl radical $\left(\mu_{5}\right)$. The initial concentration of $R$ was set at three times the initial concentration of DDP when simulating DDP pyrolysis because there are three non-ipso positions on the pyrene nucleus (the 3,6 , and 8 positions) that have the same reactivity for $\mathrm{H}$ addition as does the ipso position.

Propagation occurs through hydrogen abstraction, $\beta$-scission, and hydrogen addition via radical hydrogen transfer (RHT) and $\mathrm{H}$ atom addition steps. Reactions 4-18 show hydrogen abstraction from the alkyl chain in DDP by methylpyrenyl radicals $\left(\beta_{1}\right)$, primary alkyl and alkylpyrenyl radicals $\left(\beta_{2}, \beta_{3}, \beta_{4}\right)$, and hydrogen atoms $\left(\beta_{5}\right)$ to produce $\gamma$-DDP radicals $\left(\mu_{1}\right)$, $\alpha$-DDP radicals $\left(\mu_{2}\right)$, and all other secondary alkylpyrene radicals $\left(\mu_{3}\right)$. Note that although hydrogen abstraction can occur at any of the 12 positions in the aliphatic chain, there exist only three kinetically distinct abstraction pathways in long-chain $n$-alkylarenes (Savage and Klein, 1989). All non- $\alpha-$ and non- $\gamma$-DDP radicals share similar reactivities and consequently these can be lumped together and classified as $\mu_{3}$. Steps 4-12 are the important hydrogen abstraction steps for the pyrolysis of long-chain $n$ alkylbenzenes. Steps $13-18$ were added to model DDP pyrolysis because $\mathrm{H}$ atoms and dodecyl radicals are present in this system.

The $\mu$ radicals formed in the hydrogen abstraction steps can undergo $\beta$-scission, as shown in reactions 19-21, to produce an alkene or alkenylpyrene $\left(Q_{1}-Q_{3}\right)$ along with the corresponding alkyl or alkylpyrenyl radical $\left(\beta_{1}-\beta_{3}\right)$. Moreover, the $\mu$ radicals formed in the initiation steps can also undergo $\beta$ scission to produce pyrene $\left(Q_{4}\right)$ plus dodecyl radicals $\left(\beta_{4}\right)$ and substituted pyrenes plus hydrogen atoms $\left(\beta_{5}\right) . R$ is shown as a parenthetical product of step 22 because the elimination of the $n$-dodecyl substituent from an ipso-dodecylhydropyrenyl radical increases 
the number of aromatic positions available for hydrogen transfer.

Steps 24-36 involve hydrogen addition to peripheral aromatic carbons in the pyrene nucteus via either RHT or $\mathrm{H}$ atom addition. Hydrogen atoms add to form either ipso or non-ipso dodecylhydropyrenyl radicals in steps 30 and 31 . The remaining steps depict RHT reactions. Reactions 24-29 transfer hydrogen from primary alkyl and alkylpyrenyl radicals to ipso and non-ipso positions on pyrene nuclei. The resulting products are $\alpha$-olefins and alkenylpyrenes plus alkylhydropyrenyl radicals. Reactions 32-35 transfer hydrogen from secondary DDP radicals. These RHT steps, which Freund et al. (1991) found to be important for alkylpyrene pyrolysis, form DDP molecules with a double bond within the alkyl chain (interal olefins) plus alkylhydropyrenyl radicals. The final radical hydrogen transfer reaction, step 36, involves the transfer of hydrogen from the non-ipso positions of alkylhydropyrenyl radicals to the ipso position in DDP. We did not include $\mu_{1}$ or $\mu_{4}$ as potential radical hydrogen donors because these two radicals have very rapid $\beta$-scission steps available. Thus, RHT steps, which are slower, will not be competitive. Note that none of the hydrogen transfer steps delineated above have been included in mechanistic models for alkylbenzene pyrolysis. Indeed, it is precisely this importance of hydrogen transfer in polycyclic systems and its relative insignificance in alkylbenzenes that leads to hydrogenolytic cleavage of the strong aryl-alkyl $\mathrm{C}-\mathrm{C}$ bond being a distinguishing feature in polycyclic systems.

Chain transfer reactions (steps 37-46) shift the distribution of $\mu$ radicals and occur through hydrogen abstraction and isomerization. In steps $37-42$ a secondary DDP radical abstracts hydrogen from DDP to produce a different secondary DDP radical and regenerate DDP. Savage and Klein (1989) included the analogous steps in their model of alkylbenzene pyrolysis. Reactions $43-46$ are 1,5 hydrogen shift isomerizations. These reactions can be thought of as internal hydrogen abstraction reactions.

Termination occurs through radical recombination (steps 47-49) and disproportionation (steps 50 and 51). Steps $47-49$ are written generally because the model includes all possible bimolecular radical recombination reactions as termination steps. Some of the products that are formed through these termination steps are thermally unstable because they contain a weak benzylic $\mathrm{C}-\mathrm{C}$ bond (e.g. $\beta_{1} \beta_{1}, \beta_{2} \mu_{2}$, and $\mu_{2} \mu_{2}$ ). Thus, steps that describe the decomposition of these products have also been included in Fig. 1.

The model in Fig. 1 includes the elementary steps required to account for the formation of the primary pyrolysis products. Steps that account for the formation of secondary products have not been included. For example, ethylpyrene is a major product of DDP neat pyrolysis (Savage et al., 1989) and it is thought to arise, at least in part, from vinylpyrene, which is a primary product. The model does not include any steps to account for the conversion of vinylpyrene to ethyl- pyrene. These steps have been omitted because they have not yet been fully modeled even in alkylbenzene pyrolysis. Realizing that the model omits some secondary reactions, one should not expect the model to predict the yields of products involved in secondary reactions.

At this point, it is instructive to summarize the key features that distinguish the present mechanism for the pyrolysis of a long-chain polycyclic $n$-alkylarene from many previous mechanisms for long-chain $n$ alkylbenzenes. The mechanism in Fig. 1 includes RRD steps as an avenue for initiation, hydrogen transfer from free radicals via RHT and from direct addition of $\mathrm{H}$ atoms, and isomerization reactions involving secondary dodecylpyrene radicals. As we will show in a subsequent section, including the hydrogen transfer steps is essential for modeling DDP pyrolysis whereas the pyrolysis of long-chain alkylbenzenes could be fully described without hydrogen transfer reactions.

\section{RATE CONSTANT ESTIMATES}

The previous section presented the reaction mechanism for DDP pyrolysis. We now describe the next step in the development of a detailed chemical kinetics model, which is to estimate numerical values for each of the reaction rate constants. Our guiding philosophy in selecting values for the Arrhenius parameters was to establish a set of rate constants that (1) were internally consistent, (2) were within the range of values used previously in the literature, and (3) provided a good description of our experimental results. Previous rate constant estimates or measurements for alkylaromatics, thermochemical data, and the Evans-Polanyi relation (Boudart, 1968) were the keys to our rate constant estimation protocol. The ther. mochemical data required and the numerical values used were the difference in resonance stabilization energy ( $\triangle \mathrm{KSE}$ ) between a 1-methylpyrenyl radical and a benzyl radical $(5.1 \mathrm{kcal} / \mathrm{mol})$, and the dissociation energies of the $\mathbf{C}-\mathbf{H}$ bond in a 1-hydropyreny] radical $(37 \mathrm{kcal} / \mathrm{mol})$, the $\alpha \mathrm{C}-\mathrm{H}$ bond in toluene $(89.5 \mathrm{kcal} / \mathrm{mol})$, the $\alpha \mathrm{C}-\mathrm{C}$ bond in an alkylbenzene $(72.5 \mathrm{kcal} / \mathrm{mol})$, the $\alpha \mathrm{C}-\mathrm{H}$ bond in an alkylbenzene $(87 \mathrm{kcal} / \mathrm{mol})$, a primary $\mathrm{C}-\mathrm{H}$ bond in an $n$-alkane $(100.5 \mathrm{kcal} / \mathrm{mol})$, and a secondary $\mathrm{C}-\mathrm{H}$ bond in an $n$-alkane $(98 \mathrm{kcal} / \mathrm{mol})$. These thermochemical data were taken from a review paper by Poutsma (1990) and from the work done at NIST (Tsang, 1992; Walker and Tsang, 1990; Stein and Brown, 1991). The other parameters needed were the intrinsic activation energy (barrier height) and Evans-Polanyi $\alpha$ for each class of reactions. We took most of these parameters from Malhotra and McMillen (1990) and some from Poutsma and Dyer (1982). Using only a few different sources (i.e. groups at NIST, Oak Ridge National Laboratory, and Stanford Research Institute) for the thermochemical and kinetics data helped ensure internal consistency in the rate constant estimates. We constructed a spreadsheet that automatically recal- 
culated all of the affected rate constants if one or more of these parameters changed.

Table 2 summarizes the data used in the rate constant estimation procedure. The first column lists the reaction number that corresponds to Fig. 1. The second column tabulates the heat of reaction, and the third column lists the Arrhenius pre-exponential factor. The fourth and fifth columns list the intrinsic activation energies and the Evans-Polanyi factors, respectively. The sixth column displays the activation energies. The reaction path degeneracies (RPD) are listed in the seventh column and, finally, the value of the rate constant at $400^{\circ} \mathrm{C}$ is listed in the eighth column. The paragraphs that follow provide the details of the rate constant estimation protocol.

Malhotra and McMillen (1990) developed a mechanistic reaction model for coal liquefaction that in- cluded many of the same types of steps included in the present mechanism for DDP pyrolysis. We used their rate constant estimation regimen to establish Arrhenius parameters for the following steps in our mechanism: reverse radical disproportionation (2-3), hydrogen abstraction involving two benzylic centers (5), hydrogen abstraction by $H$ atoms $(16-18), \beta-$ scission of hydroaryl radicals (22-23), radical hydrogen transfer (24-29, 34-36), and $\mathrm{H}$ atom addition (30-31). The numbers in parentheses refor to the rcaction numbers in Fig. 1 and in Table 2. We also extended Malhotra and McMillen's protocol for hydrogen abstraction reactions, which considered only reactions between benzylic centers, to estimate rate constants for steps 4 and $6-15$ in our model. We used the pre-exponential factor and Evans-Polanyi $\alpha$ given by Malhotra and McMillen (1990), but we took

Table 2. Rate constant estimates

\begin{tabular}{|c|c|c|c|c|c|c|c|c|}
\hline Elementary step & & $\begin{array}{c}\Delta H(R \times n) \\
(\mathrm{kcal} / \mathrm{mol})\end{array}$ & $\underset{(1 / \mathrm{mol} / \mathrm{s})}{\log \mathrm{A}}$ & $\begin{array}{c}E_{0} \\
(\mathrm{kcal} / \mathrm{mol})\end{array}$ & $\alpha$ & $\begin{array}{c}E_{a} \\
\text { (kcal/mol) }\end{array}$ & RPD & $\begin{array}{c}k(9) 400^{\circ} \mathrm{C} \\
(1 / \mathrm{mol} / \mathrm{s})\end{array}$ \\
\hline \multirow[t]{3}{*}{ Initiation } & 1 & 67.4 & 16 & 0.0 & 1 & 67.4 & 1 & $1.3 \times 10^{-6}$ \\
\hline & 2 & 44.9 & 8.6 & 9.0 & 0.82 & 45.8 & 4 & $2.1 \times 10^{-6}$ \\
\hline & 3 & 44.9 & 8.6 & 9.0 & 0.82 & 45.8 & 2 & $1.0 \times 10^{-6}$ \\
\hline Hydrogen & 4 & 13.6 & 8 & 13.5 & 0.65 & 22.3 & 2 & $1.1 \times 10^{1}$ \\
\hline \multirow[t]{14}{*}{ abstraction } & 5 & -2.5 & 8 & 16.0 & 0.35 & 15.1 & 2 & $2.4 \times 10^{3}$ \\
\hline & 6 & 13.6 & 8 & 13.5 & 0.65 & 22.3 & 18 & $1.0 \times 10^{2}$ \\
\hline & 7 & -2.5 & 8 & 12.6 & 0.35 & 11.7 & 2 & $3.1 \times 10^{4}$ \\
\hline & 8 & -18.6 & 8 & 13.5 & 0.35 & 7.0 & 2 & $1.1 \times 10^{6}$ \\
\hline & 9 & 2.5 & 8 & 12.6 & 0.35 & 11.7 & 18 & $2.8 \times 10^{5}$ \\
\hline & 10 & -2.5 & 8 & 12.6 & 0.35 & 11.7 & 2 & $3.1 \times 10^{4}$ \\
\hline & 11 & -18.6 & 8 & 13.5 & 0.35 & 7.0 & 2 & $1.1 \times 10^{6}$ \\
\hline & 12 & -2.5 & 8 & 12.6 & 0.35 & 11.7 & 18 & $2.8 \times 10^{5}$ \\
\hline & 13 & -2.5 & 8 & 12.6 & 0.35 & 11.7 & 2 & $3.1 \times 10^{4}$ \\
\hline & 14 & -18.6 & 8 & 13.5 & 0.35 & 7.0 & 2 & $1.1 \times 10^{6}$ \\
\hline & 15 & -2.5 & 8 & 12.6 & 0.35 & 11.7 & 18 & $2.8 \times 10^{5}$ \\
\hline & 16 & -6 & 10.4 & 13.3 & 0.25 & 11.8 & 2 & $7.7 \times 10^{6}$ \\
\hline & 17 & -22.1 & 10.4 & 13.3 & 0.25 & 7.7 & 2 & $1.6 \times 10^{8}$ \\
\hline & 18 & -6 & 10.4 & 13.3 & 0.25 & 11.8 & 18 & $6.9 \times 10^{7}$ \\
\hline \multirow[t]{5}{*}{ Beta scission } & 19 & & 15 & & & 24.0 & 1 & $1.6 \times 10^{7}$ \\
\hline & 20 & & 15.2 & & & 43.3 & 1 & $1.4 \times 10^{1}$ \\
\hline & 21 & & 12.7 & & & 29.1 & 2 & $3.6 \times 10^{3}$ \\
\hline & 22 & & 14 & & & 20.0 & 1 & $3.2 \times 10^{7}$ \\
\hline & 23 & 37 & 13.6 & 9.0 & 0.78 & 37.9 & 2 & $4.0 \times 10^{1}$ \\
\hline Hydrogen & 24 & -1.17 & 7.8 & 16.5 & 0.35 & 16.1 & 2 & $7.5 \times 10^{2}$ \\
\hline \multirow[t]{12}{*}{ addition } & 25 & -1.17 & 7.8 & 16.5 & 0.35 & 16.1 & 2 & $7.5 \times 10^{2}$ \\
\hline & 26 & -1.17 & 7.8 & 16.5 & 0.35 & 16.1 & 2 & $7.5 \times 10^{2}$ \\
\hline & 27 & -1.17 & 7.8 & 16.5 & 0.35 & 16.1 & 2 & $7.5 \times 10^{2}$ \\
\hline & 28 & -1.17 & 7.8 & 16.5 & 0.35 & 16.1 & 2 & $7.5 \times 10^{2}$ \\
\hline & 29 & -1.17 & 7.8 & 16.5 & 0.35 & 16.1 & $\overline{2}$ & $7.5 \times 10^{2}$ \\
\hline & 30 & -37 & 10.3 & 6.5 & 0.11 & 2.3 & 1 & $3.5 \times 10^{9}$ \\
\hline & 31 & -37 & 10.3 & 6.5 & 0.11 & 2.3 & 1 & $3.5 \times 10^{9}$ \\
\hline & 32 & & 7.8 & & & 21.7 & 2 & $1.1 \times 10^{1}$ \\
\hline & 33 & & 7.8 & & & 21.7 & 2 & $1.1 \times 10^{1}$ \\
\hline & 34 & -1.67 & 7.8 & 16.5 & 0.35 & 15.9 & 2 & $8.6 \times 10^{2}$ \\
\hline & 35 & -1.67 & 7.8 & 16.5 & 0.35 & 15.9 & 2 & $8.6 \times 10^{2}$ \\
\hline & 36 & 0 & 7.8 & 16.5 & 0.65 & 16.5 & 2 & $5.5 \times 10^{2}$ \\
\hline \multirow{10}{*}{$\begin{array}{l}\text { Chain } \\
\text { transfer }\end{array}$} & 37 & -16.1 & 8 & 13.5 & 0.35 & 7.9 & 2 & $5.6 \times 10^{5}$ \\
\hline & 38 & 0 & 8 & 12.6 & 0.35 & 12.6 & 18 & $1.5 \times 10^{5}$ \\
\hline & 39 & 16.1 & 8 & 13.5 & 0.65 & 24.0 & 2 & $3.3 \times 10^{\circ}$ \\
\hline & 40 & 16.1 & 8 & 13.5 & 0.65 & 24.0 & 18 & $3.0 \times 10^{1}$ \\
\hline & 41 & 0 & 8 & 12.6 & 0.35 & 12.6 & 2 & $1.6 \times 10^{4}$ \\
\hline & 42 & -16.1 & 8 & 13.5 & 0.35 & 7.9 & 2 & $5.6 \times 10^{3}$ \\
\hline & 43 & & 10 & & & 12.6 & 1 & $8.1 \times 10^{5}$ \\
\hline & 44 & & 10 & & & 24.0 & 1 & $1.6 \times 10^{2}$ \\
\hline & 45 & & 10 & & & 12.6 & 0.11 & $8.9 \times 10^{4}$ \\
\hline & 56 & & 10 & & & 7.9 & 0.11 & $3.1 \times 10^{6}$ \\
\hline
\end{tabular}


$E_{0}=13.5$ and $12.6 \mathrm{kcal} / \mathrm{mol}$, respectively, for thermoneutral abstraction reactions between an aliphatic and benzylic center and between two aliphatic centers, respectively. These values for $E_{0}$ were determined from a listing of hydrogen abstraction rate constants given as Table IX by Poutsma and Dyer (1982). A brief summary of our rate constant estimation procedure for the other steps in the mechanism is given below.

\section{Initiation}

Step 1 depicts the homolytic dissociation of the bond between the $\alpha$ - and $\beta$-carbons in DDP. These dissociation reactions of large molecules typically proceed with Arrhenius pre-exponential factors of $10^{16 \pm 1} \mathrm{~s}^{-1}$ (Benson, 1976). Therefore, we took $A=10^{16} \mathrm{~s}^{-1}$ for step 1. Further, we took the activation energy for step 1 to be the $72.5 \mathrm{kcal} / \mathrm{mol}$ activation energy for the analogous reaction in a long-chain n-alkylbenzene (Tsang, 1992; Walker and Tsang, 1990) less the $5.1 \mathrm{kcal} / \mathrm{mol}$ difference in resonance stabilization energy (Poutsma, 1990) to obtain $67.4 \mathrm{kcal} / \mathrm{mol}$.

\section{B-Scission}

Poutsma and Dyer's (1982) estimates for $\beta$-scission Arrhenius parameters for 1, 4-diphenylbutane pyrolysis provide a basis for estimating the analogous parameters for DDP pyrolysis. They took $A=10^{15} \mathrm{~s}^{-1}$ and $E_{a}=28 \mathrm{kcal} / \mathrm{mol}$ for $\beta$-scission of a $\gamma$ radical, which is analogous to our step 19 . We used the same pre-exponential factor but subtracted $4 \mathrm{kcal} / \mathrm{mol}$ from $E_{a}$ to account for the large fraction of the additional resonance stabilization energy in the 1-methylpyrenyl radical relative to a benzyl radical that will appear in the transition state. This $4 \mathrm{kcal} / \mathrm{mol}$ difference was determined empirically. Poutsma and Dyer took $A=10^{15.2} \mathrm{~s}^{-1}$ and $E_{a}=38.2 \mathrm{kcal} / \mathrm{mol}$ for $\beta$-scission of the $\alpha$ radical, which is analogous to our step 20. We used the same A factor, but increased $E_{a}$ by the $\triangle$ RSE of $5.1 \mathrm{kcal} / \mathrm{mol}$ because the $\alpha$-DDP radical is more stable than the $\alpha$ radical in diphenylbutane. Step 21 is $\beta$-scission of non- $\alpha$ and non- $\gamma$ secondary DDP radicals. The Arrhenius parameters for this step should be comparable to those for the $\beta$-scission of a longchain secondary $n$-alkyl radical. The kinetics compilation of Allara and Shaw (1980) shows that Arrhenius parameters of $A=10^{12.7} \mathrm{~s}^{-1}$ and $E_{\mathrm{a}}=29.1 \mathrm{kcal} / \mathrm{mol}$ are representative for this type of reaction so we used these values in our model for step 21.

\section{Radical hydrogen transfer}

Steps 32 and 33 depict hydrogen transfer from an $\alpha$-DDP radical to ipso and non-ipso positions on the pyrene nucleus. Freund et al. (1991) showed that this type of RHT step is important for long-chain $n$-alkylarenes. They used thermochemical and kinetics data to estimate that the upper bound for the activation energy for this step should be $29 \mathrm{kcal} / \mathrm{mol}$. A lack of additional data for this type of RHT step prevented them from making a good a priori estimate of the actual activation energy. They did report, however, that using an activation energy of $25.0 \mathrm{kcal} / \mathrm{mol}$ for this step in a numerical reaction model led to model calculations that were consistent with their experimental results. We also treated the activation energy for these RHT steps as an adjustable parameter in our model of DDP pyrolysis. Using an activation energy of $21.7 \mathrm{kcal} / \mathrm{mol}$ provided a good representation of our experimental data. We took $A=10^{7.8} \mathrm{~s}^{-1}$ to be consistent with the pre-exponential factors used in all other RHT steps.

\section{Isomerization}

Steps 43-46 account for isomerization reactions (1, 5 shift of a hydrogen atom) of secondary DDP radicals, which likely proceed through a six-memberedring transition state. The pre-exponential factor for these steps was taken as $A=10^{10} \mathrm{~s}^{-1}$ and the activation energy was taken to be equal to the activation energy of the analogous bimolecular hydrogen abstraction step (Benson, 1976). These estimates are consistent with the literature (Allara and Shaw, 1980; Dobe et al., 1987; Edelson and Allara, 1980). Finally, note that the reaction path degeneracy for steps 45 and 46 is given as 0.11 in Table 2 . This value is not the true RDP, but rather it accounts for the lumping scheme used in writing the mechanism. The group $\mu_{3}$ includes all nine of the non- $\alpha$ and non- $\gamma$ secondary DDP radicals, but only one of those radicals can isomerize to form the $\alpha$ radical. Likewise, only one of the nine can undergo a 1, 5 shift to form the $\gamma$ radical. Thus, to get the correct isomerization rate for steps 45 and 46 one needs to multiply the $\mu_{3}$ concentration by $1 / 9$, or 0.11 . We elected to show this lumping effect in the RPD.

\section{Termination}

The model includes all possible recombination and disproportionation reactions as termination steps. We set the rate constants for recombination reactions equal to $10^{10.5} \mathrm{l} / \mathrm{mol} \mathrm{s}$ and the rate constants for disproportionation equal to $10^{8} \mathrm{l} / \mathrm{mol} \mathrm{s}$.

Some of the Arrhenius parameters listed in Table 2 differ from those we used previously for analogous reactions in modeling methyl- and ethylpyrene pyrolysis (Smith and Savage, 1992) and some differ from values used by Freund et al. (1991) for $n$-butylpyrene pyrolysis. The differences with our earlier work arise from our employing an improved rate constant estimation protocol here. The differences with Freund et al. arise primarily from our using different values for some key thermochemical data (e.g. $\triangle$ RSE). In both cases, however, the net effect of the different Arrhenius parameters on the numerical values of the rate constants is often within the uncertainty of the estimates. For example, the present pre-exponential factor for the reverse of radical disproportionation is higher than the value of $10^{8.0} 1 / \mathrm{mol} \mathrm{s}$ used in our ethylpyrene pyrolysis model, and the activation energy is $4.5 \mathrm{kcal} / \mathrm{mol}$ higher. Since both of the Arrhenius parameters changed in the same direction, however, their 
changes are offsetting and the rate constant for RRD does not differ appreciably for the two models. The values at $400^{\circ} \mathrm{C}$ are $5.0 \times 10^{-6} \mathrm{l} / \mathrm{mol} \mathrm{s}$ for ethylpyrene and $2.1 \times 10^{-6} \mathrm{l} / \mathrm{mol} \mathrm{s}$ for DDP for analogous reactions. As another example, note that $A$ and $E_{\alpha}$ for hydrogen abstraction by carbon-centered radicals differ from the earlier model, but the changes are typically in the same direction (i.e. both are lower in the present model). Thus, the net effect of these changes will be small, and the numerical value of the rate constant used in the model will differ only slightly. For example, abstraction of an $\alpha$ hydrogen in DDP by a primary alkyl radical has a rate constant of $1.1 \times 10^{6} \mathrm{l} / \mathrm{mol} \mathrm{s}$ at $400^{\circ} \mathrm{C}$ in the present model, whereas the rate constant for abstraction of an $\alpha$ hydrogen in ethylpyrene by an ethyl radical was $8.1 \times 10^{5} \mathrm{l} / \mathrm{mol} \mathrm{s}$.

\section{MODELING RESULTS AND DISCUSSION}

The pyrolyses of DDP neat and in a benzene diluent were simulated using Acuchem, a reaction modeling software package developed by the National Institute of Standards and Technology (Braun et al., 1988). Given initial concentrations, a set of reactions, and the corresponding reaction rate constants, the program sets up and solves the governing differential equations to calculate the temporal variation of the species' concentrations.

Figure 2 displays the model's prediction (solid lines) for the molar yields of DDP, methylpyrene, and dodecane for DDP neat pyrolyses at 375,400 , and $425^{\circ} \mathrm{C}$. Experimental data (Savage et al,, 1989) are provided as discrete points for comparison. We selected the methylpyrene and dodecane yields for these figures because these two products are representatives from the two major primary pyrolysis pathways (Smith and Savage, 1991a, c). Methylpyrene is the major product from the pathway that is analogous to the dominant pathway in alkylbenzene pyrolysis. Dodecane forms along with pyrene in the aryl-alkyl $\mathrm{C}-\mathrm{C}$ bond cleavage pathway, which is unique to polycyclic alkylarenes. We selected dodecane rather than pyrene as the representative from this second pathway because dodecane forms exclusively through this primary pathway. Pyrene, on the other hand, can form through secondary reactions such as dealkylation of primary products. As discussed earlier, secondary steps were not included in the model.

Figure 2 shows that the model tends to underpredict the reactivity of DDP at all three temperatures, but the model predictions are often within the estimated experimental uncertainty of $\pm 15 \%$ of the reported values. The formation of methylpyrene is captured well by the model. Its predictions are essentially quantitative at 375 and $400^{\circ} \mathrm{C}$, but the predictions are low at $425^{\circ} \mathrm{C}$. The production of $n$-dodecane, which forms in the aryl-alkyl $\mathrm{C}-\mathrm{C}$ bond cleavage pathway, coincides with the model predictions at $\mathbf{3 7 5}$ and $425^{\circ} \mathrm{C}$, but a larger diserepancy between the experimental and model results appear at $400^{\circ} \mathrm{C}$. Overall, the agreement between the calculated molar yields and the experimental molar yields from DDP neat
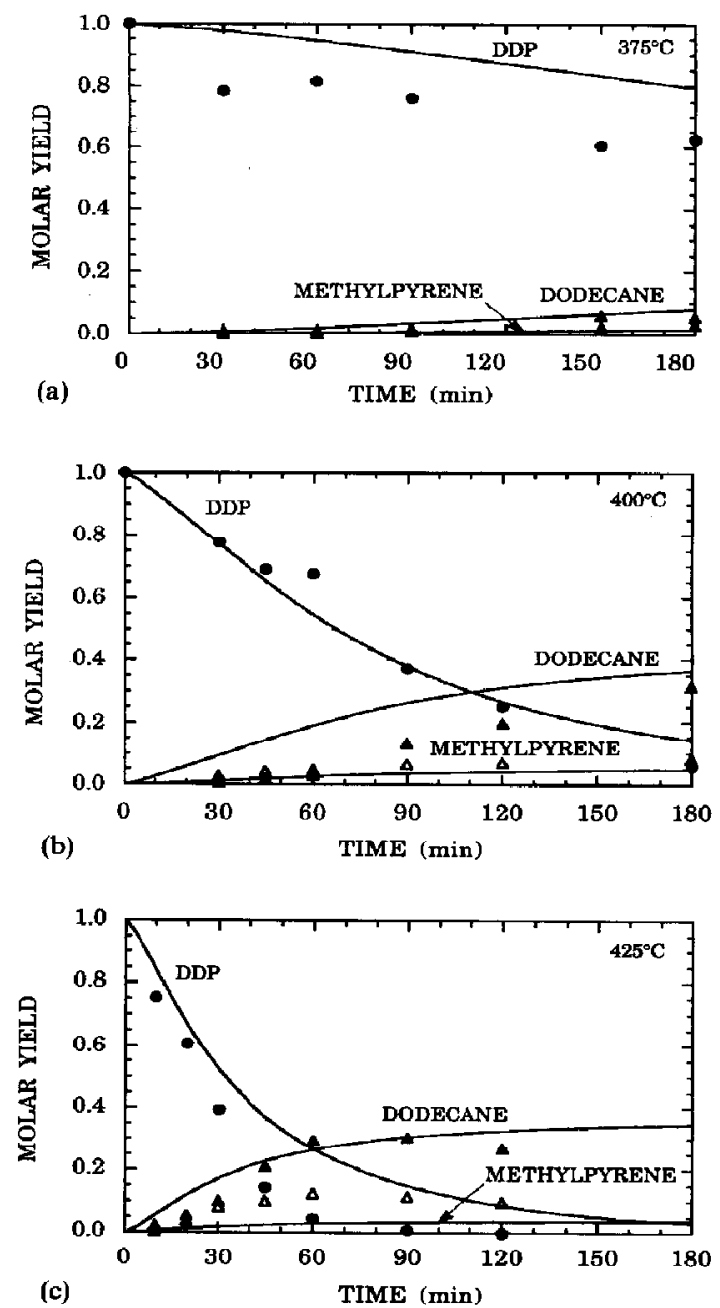

Fig. 2. Model predictions and experimental results (Savage et al., 1989) for DDP neat pyrolysis at (a) $375^{\circ} \mathrm{C}$, (b) $400^{\circ} \mathrm{C}$, (c) $425^{\circ} \mathrm{C}$.

pyrolysis is reasonably good at all three temperatures. We therefore conclude that the model accurately accounts for the effects of time and temperature on the neat pyrolysis of DDP.

To test further the ability of the reaction model to reflect experimental observations, we note that Savage et al. (1989) reported that the neat pyrolysis of DDP was autocatalytic. One of the characteristics of an autocatalytic reaction is an inflection point in the temporal variation of the reactant yield. Figure 2 shows that the model predicts this feature at a DDP conversion of about $20 \%$. Moreover, in an autocatalytic reaction the rate increases with conversion, reaches a maximum, and then declines. Thus, to verify more explicitly that the model does indeed predict autocatalytic kinetics we offer Fig. 3. The rate of disappearance of DDP calculated by the model is given as a function of the DDP conversion for neat pyrolysis at $400^{\circ} \mathrm{C}$. The curve in Fig. 3 clearly exhibits 


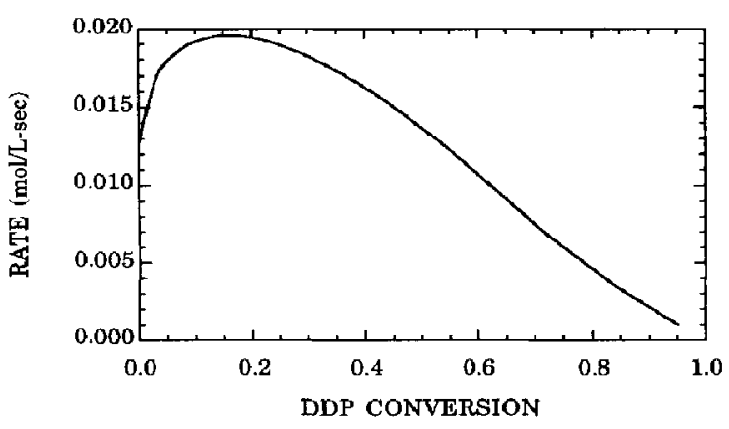

Fig. 3. Model prediction of autocatalysis in DDP neat pyrolysis at $400^{\circ} \mathrm{C}$.

a maximum, which is consistent with the autocatalysis observed by Savage et al. (1989). The maximum rate in Fig. 3 occurs at a DDP conversion of 0.18 . For the DDP pyrolysis simulations at $425^{\circ} \mathrm{C}$, the maximum occurred at a conversion of 0.10 , and for the simulations a $375^{\circ} \mathrm{C}$ the maximum occurred at a conversion of about 0.20 .

Having demonstrated that the detailed chemical kinetic model for DDP is largely consistent with the neat pyrolysis results, we next explore the ability of the reaction model to predict the effect of the initial concentration on DDP pyrolysis. Figure 4 compares model predictions with the experimental data of Smith and Savage (1991a) for DDP pyrolyses at different initial concentrations. These reactions were conducted at $400^{\circ} \mathrm{C}$ and $300 \mathrm{~min}$. Inspection of Fig. 4 shows that the model captured the major trends in the data. These trends are a precipitous decrease in the DDP yield and an accompanying increase in the dodecane yield at high concentrations and a maximum in the methylpyrene yield at an intermediate concentration. In addition to capturing the qualitative trends in the data, the model also provided good quantitative predictions of the dodecane and methylpyrene molar yields. Quantitative agreement for the DDP yield was not achieved, however. Rather, the model underpredicted the reactivity of DDP at high concentrations, but overpredicted it at low concentrations. The calculated rate being slower than the experimental rate at high concentrations was also evident in the neat pyrolysis results of Fig. 2.

Figures 2-4, taken together, lead us to conclude that the detailed chemical kinetics model described herein did an adequate job of describing DDP pyrolysis. Its qualitative predictions about the effects of time, temperature, and concentration were correct in all cases. Further, the model provided a semi-quantitative prediction of the product yields observed experimentally. The lack of perfect agreement between the model and the experimental observations can be accounted for, in part, by the uncertainties in the rate constant estimates and in the experimental measurements. Of course, bettter agreement between the model and experimental results might have been obtained by adjusting the reaction rate constants, but

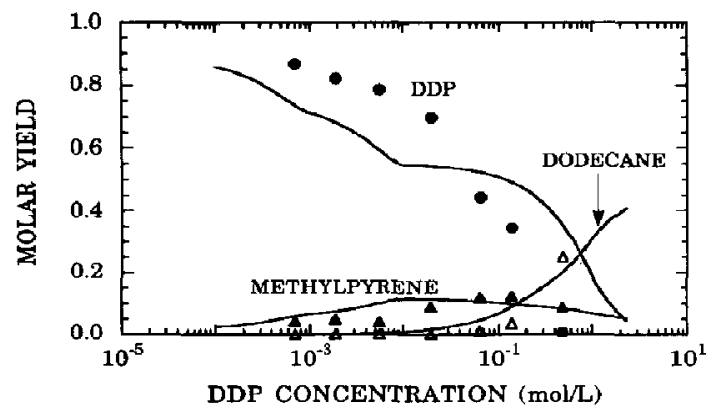

Fig. 4. Model prediction and experimental result ( $\$$ mith and Savage, 1991a) for the effect of the initial DDP concentration on product yields at $400^{\circ} \mathrm{C}$ and $300 \mathrm{~min}$.

Table 3. Molar yields calculated for DDP neat pyrolysis at $400^{\circ} \mathrm{C}$ and $90 \mathrm{~min}$

\begin{tabular}{lcll}
\hline Species & Molar yield & Species & Molar yield \\
\hline $\mathrm{A}$ & $3.8 \times 10^{-1}$ & $\mathbf{R}$ & $3.3 \times 10^{0}$ \\
$\beta_{1} \mathrm{H}$ & $3.6 \times 10^{-2}$ & $\beta_{1}$ & $1.9 \times 10^{-9}$ \\
$\beta_{2} \mathrm{H}$ & $3.3 \times 10^{-2}$ & $\beta_{2}$ & $3.9 \times 10^{-12}$ \\
$\beta_{3} \mathrm{H}$ & $5.0 \times 10^{-3}$ & $\beta_{3}$ & $4.5 \times 10^{-13}$ \\
$\beta_{4} \mathrm{H}$ & $2.6 \times 10^{-1}$ & $\beta_{4}$ & $2.8 \times 10^{-11}$ \\
$\beta_{5} \mathrm{H}$ & $1.1 \times 10^{-4}$ & $\beta_{5}$ & $8.3 \times 10^{-17}$ \\
$\mathrm{Q}_{1}$ & $3.2 \times 10^{-2}$ & $\mu_{1}$ & $2.3 \times 10^{-13}$ \\
$\mathrm{Q}_{2}$ & $3.4 \times 10^{-2}$ & $\mu_{2}$ & $3.5 \times 10^{-7}$ \\
$\mathrm{Q}_{3}$ & $1.0 \times 10^{-3}$ & $\mu_{3}$ & $2.0 \times 10^{-11}$ \\
$\mathrm{Q}_{4}$ & $2.7 \times 10^{-1}$ & $\mu_{4}$ & $1.1 \times 10^{-12}$ \\
$\mathbf{P}_{2}$ & $1.1 \times 10^{-4}$ & $\mu_{5}$ & $6.1 \times 10^{-8}$ \\
$\mathrm{P}_{3}$ & $1.6 \times 10^{-3}$ & $\beta_{1} \beta_{1}$ & $1.2 \times 10^{-5}$ \\
$\mathrm{P}_{4}$ & $1.0 \times 10^{-3}$ & $\mu_{2} \mu_{2}$ & $4.7 \times 10^{-3}$ \\
$\mathrm{I}_{2}$ & $2.6 \times 10^{-1}$ & $\beta_{1} \mu_{7}$ & $2.4 \times 10^{-4}$ \\
$\mathrm{I}_{3}$ & $1.0 \times 10^{-3}$ & Term & $1.1 \times 10^{-2}$ \\
\hline
\end{tabular}

lacking more precise thermochemical data, we felt that such adjustments were not warranted.

Having established the ability of the detailed chemical reaction model to predict experimental observations, we now consider its predictions for the yields of some of the products and reaction intermediates. Table 3 lists the molar yield calculated for each of the products and radical intermediates from DDP neat pyrolysis at $400^{\circ} \mathrm{C}$ and $90 \mathrm{~min}$. Pyrene $\left(Q_{4}\right)$, dodecane $\left(\beta_{4} \mathrm{H}\right)$, and the internal olefin $I_{2}$ (double bond between the $\alpha$ and $\beta$ carbons) possess the highest yields. Pyrene and dodecane were the major products observed experimentally, but high yields of the internal olefin were not reported for DDP pyrolysis (Savage et al., 1989). In other related studies, however, Smith (1992) tentatively identified the analogous internal olefin as a product from 1-decylpyrene pyrolysis at $400^{\circ} \mathrm{C}$, and Freund et al. (1991) identified the internal olefin as a key product from alkylpyrene pyrolysis. The failure to observe the internal olefin in the high yields predicted by the model for the batch reactor experiments of Savage et al. (1989) is likely due to the conversion of the internal olefin to other products through secondary reactions. Such secondary reactions were not included in the model, but they are expected to be rapid 
given the reactivity of the double bond in the internal olefin (Church and Gleicher, 1979). Support for this hypothesis can be found by comparing the results of Freund et al. (1991) and Savage et al. (1989). Freund et al. (1991) employed an open system, and the primary pyrolysis products could escape from the reaction zone without undergoing secondary reactions. Thus, the internal olefin survived and Freund et al. (1991) were able to detect it. Savage et al. (1989), on the other hand, used a closed system for the pyrolyses, so the primary products with a propensity for participating in secondary reactions were free to do so. A similar argument explains why the model predicts measurable yields of vinylpyrene, but no vinylpyrene was observed experimentally (Savage et al., 1989). One possible reaction for vinylpyrene is its reduction to ethylpyrene. This behavior is consistent with the rapid conversion of styrene to ethylbenzene, which has been suggested as a reaction pathway by previous investigators (Klein and Virk, 1983; Savage and Klein, 1987a).

Table 3 shows that the radicals $\mu_{2}$ and $\mu_{5}$ had molar yields at least an order of magnitude higher than the yield of any other radical. The high yield for the $\alpha$-DDP radical $\left(\mu_{2}\right)$ can be accounted for by noting that it is formed in the most rapid hydrogen abstraction step, but it decomposes only through relatively slow $\beta$-scission and RHT reaction steps. We will return to the importance of the $\alpha$-DDP radical in a subsequent section of this paper.

In addition to exploring the concentrations of products and radical intermediates, the detailed chemical kinetics model can be used to examine the rates of the different hydrogenolysis steps. Such detailed information would be difficult, if not impossible, to obtain from experiments. Figure 5 displays the rates of the six different steps that transfer hydrogen to the ipso position in DDP as function of DDP conversion at $400^{\circ} \mathrm{C}$. Hydrogen transfer by 1-alkylhydropyrenyl radicals $\left(\mu_{5}\right)$ was the most rapid hydrogen transfer step over essentially the entire conversion range. Hydrogen transfer by $\alpha$-DDP radicals $\left(\mu_{2}\right)$ was the second most rapid step, and it proceeded at about $20 \%$ of the rate of the most rapid RHT step. RRD was the third fastest hydrogen transfer step at most con-

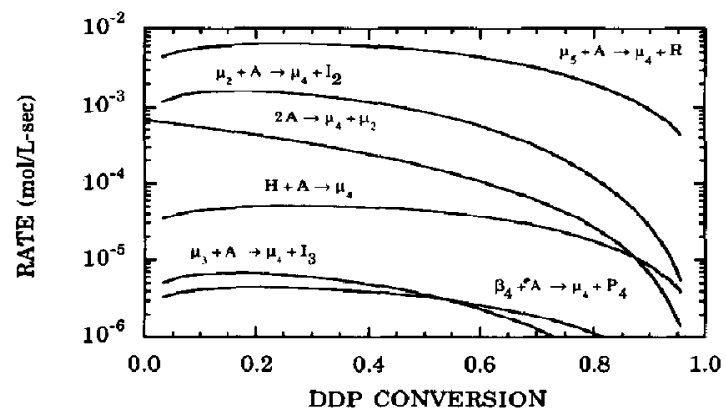

Fig. 5. Hydrogen addition rates calculated for DDP neat pyrolysis at $400^{\circ} \mathrm{C}$.

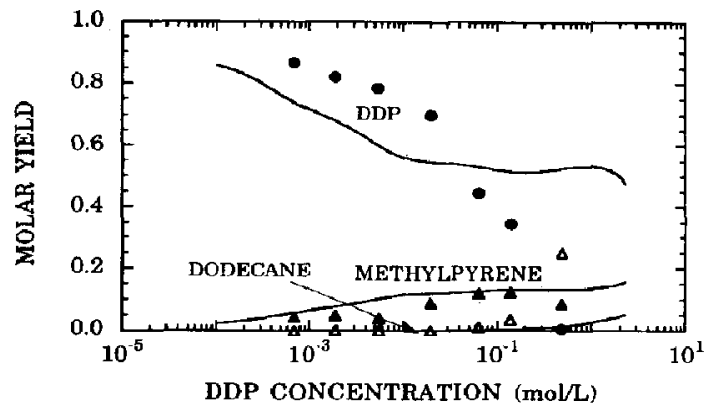

Fig. 6. Prediction of model without RHT steps and experimental results (Smith and Savage, 1991a) for the effect of the initial DDP concentration on product yields at $400^{\circ} \mathrm{C}$ and $300 \mathrm{~min}$.

versions. It was the most rapid step at very low conversions where initiation reactions still dominated. The rate of hydrogen atom addition was almost two full orders of magnitude less than the rate of hydrogen transfer by alkylhydropyrenyl radicals. As a consequence, it appears that hydrogen atoms have a minor role as hydrogenolysis agents, a conclusion that is consistent with earlier experimental work for DDP pyrolysis (Smith and Savage, 1991a, c). Figure 5 also displays the rates of two other RHT steps. These steps, which involve secondary DDP radicals and primary dodecyl radicals as hydrogen donors, are slow during DDP pyrolysis. To summarize, Fig. 5 shows that RHT from $\alpha$-dodecylpyrene radicals and alkylhydropyrenyl radicals are the most important hydrogenolysis steps, and that RRD is also important because of its unique role as an initiation step.

We explored the influence of the RHT steps further by excluding these reactions (steps $24-29,32-36$ in Fig. 1) from the model and then simulating DDP pyrolysis. All other reactions were retained, and the values of all rate constants remained unchanged. Figure 6 compares the predictions of this model without RHT steps with the experimental data shown previously in Fig. 4. The model prediction, given by the solid line, tracks the data as well as the full model did at low concentrations. At higher concentrations, however, the revised model fails to capture even the qualitative trends in the data. The precipitous decrease in DDP yield and the rapid formation of dodecane observed experimentally are not predicted. This analysis confirms that RHT constitutes important hydrogenolysis steps, and it further shows that these steps are most important at high initial concentrations.

\section{SENSITIYITY ANALYSIS}

Recognizing that the predictions of a detailed chemical kinetics model are only as reliable as the kinetics parameters used in the model, we sought to determine the sensitivity of the model results to small changes in the rate constant estimates. Therefore, we performed a sensitivity analysis and used the methods and software recently developed by Turanyi $(1990 \mathrm{a}, \mathrm{b})$. 
Before conducting the sensitivity analysis, we first reduced the number of reactions and reacting species in the mechanism to reduce the computation time required. We took advantage of the simulation results presented previously to eliminate reactions that were not kinetically significant. For example, the reduced mechanism includes only the termination reactions involving the radicals present in the highest concentrations. Table 3 shows that $\alpha$-dodecylpyrene radicals $\left(\mu_{2}\right)$, non-ipso alkylhydropyrenyl radicals $\left(\mu_{5}\right)$, and methylpyrenyl radicals $\left(\beta_{1}\right)$ had much higher yields than any other radicals. Therefore, termination reactions involving these radicals are expected to be dominant, and termination reactions of less abundant radicals will be less important. Therefore, we included only the termination reactions involving these radicals in the reduced mechanism. A further simplification was to eliminate hydrogen abstraction by $\mu_{1}$ radicals because the competing $\beta$-scission steps are much faster. We also restricted methylpyrenyl radicals to abstracting only $\alpha$-DDP hydrogen atoms because abstraction at all other alkyl positions was nearly two orders of magnitude slower. Furthermore, we retained only $\mu_{2}$ and $\mu_{s}$ as radical hydrogen donors because the RHT steps were slower than hydrogen abstraction for all of the other potential radical hydrogen donors. Finally, we lumped all primary alkyl radicals together as a single pseudo species termed $\beta$. Grouping these radicals together is reasonable because the reactivity of long-chain primary alkyl radicals is a very weak function of the alkyl chain length. The reduced mechanism is shown as the first column in Table 4. The identities of the species in Table 4 are the same as in Fig. 1 except for $\beta$, which is the lumped concentration of all primary alkyl radicals.

Returning to the sensitivity analysis, we note that the concentrations of the species in a constant-volume batch reaction can be described generally by eq. (1):

$$
\frac{\mathrm{d} c}{\mathrm{~d} t}=\mathbf{f}(\mathbf{c}, \mathbf{k}), \quad c(0)=c 0
$$

where $c$ is a vector of species concentrations and $k$ is a vector of rate parameters. We desired to determine the effect of a small change in the reaction rate constants on the calculated species concentrations. Equation (2) expresses this effect in terms of a Taylor series expansion:

$$
c_{i}(t, k+\Delta k)=c_{i}(t, k)+\sum_{j=1}^{m} \frac{\partial c_{i}}{\partial k_{j}} \Delta k_{j}+\cdots
$$

The quantities $\partial c_{i} / \partial k_{j}$ are the first-order local concentration sensitivity coefficients, and they represent a linear approximation of the dependence of the species concentrations on rate constant changes. These are the coefficients calculated in Turanyi's (1990a, b) sensitivity analysis software package KINAL, and they comprise the elements in the sensitivity matrix.

The sensitivity coefficients calculated for the neat pyrolysis of DDP at $400^{\circ} \mathrm{C}$ for $120 \mathrm{~s}$ using the reduced reaction mechanism are shown in Table 4 . These values are normalized and dimensionless sensitivity coefficients, which were calculated as $\left(\partial c_{t} / \partial k_{j}\right)\left(k_{j} / c_{i}\right)$. Table 4 lists only those coefficients with absolute values greater than 0.001 .

DDP (A), methylpyrene $\left(\beta_{1} H\right)$, vinylpyrene $\left(Q_{2}\right)$, and pyrene $\left(Q_{4}\right)$ are representative of the key products from DDP pyrolysis, so our discussion of the scnsitivity analysis results will focus on these products. Inspection of Table 4 reveals that the calculated concentration of DDP is most strongly influenced by the rate constants for steps 3,14, 2, and 37. These steps are the two initiation steps by RRD, the transfer of hydrogen from $\alpha$-DDP radicals to non-ipso positions on DDP, and the fission of a termination product into two $\alpha$-DDP radicals. Thus, these steps are the most important in determining DDP pyrolysis kinetics.

The calculated concentration of methylpyrene is most sensitive to the rate constants for steps $1,15,29$, and 37. Step 1 is the homolytic dissociation of the weakest $\mathrm{C}-\mathrm{C}$ bond in the alkyl chain. This step produces methylpyrenyl radicals, which can subsequently abstract hydrogen to form methylpyrene. Step 15 is a chain transfer step in which $\alpha$-DDP radicals are converted to $\gamma$-DDP radicals. The $\gamma$-DDP radicals can then undergo $\beta$-scission to produce a methylpyrenyl radical. Steps 29 and 37 involve the recombination and subsequent dissociation of $\alpha$-DDP radicals.

The concentration of vinylpyrene calculated from the reaction model is most influenced by the kinetics of steps $20,29,37$, and 3 . Step 20 , the $\beta$-scission event that forms vinylpyrene is by far the most important step. The termination and initiation steps that involve $\alpha$-DDP radicals are also significant, however.

The calculated concentration of pyrene is most sensitive to the rates of steps $3,14,2,29$, and 37 . The only propagation step of these five reactions is step 14, RHT from $\alpha$-DDP radicals to non-ipso positions on pyrene-containing species.

The discussion above shows that just a few reactions largely control the kinetics of DDP pyrolysis and the product selectivities. These key reactions are the initiation steps (1-3) and several steps involving $\alpha$-DDP radicals as either reactants (steps $14,15,20$, 29) or products (step 37). These important steps involving $\alpha$-DDP radicals include RHT, hydrogen abstraction, $\beta$-scission, and recombination reactions. Moreover, the RHT step is important not only in influencing the product selectivities, but also in determining reaction kinetics. Note that this result from the sensitivity analysis is fully consistent with the high yield of $\alpha$-DDP radicals noted earlier in our discussion of Table 3 . These radicals are important because they are easily formed and have slow, but competing, channels for reaction.

\section{SUMMARY AND CONCLUSIONS}

(1) The detailed chemical kinetics model described in this paper is consistent with experimental observations reported previously for DDP pyrolysis. The model accurately predicted the effects of holding time, temperature, and initial concentration on the kinetics and product yields. The model also predicted the 
Table 4. Normalized sensitivity

\begin{tabular}{|c|c|c|c|c|c|c|c|c|c|c|}
\hline & A & $\mathbf{R}$ & $\beta_{1}$ & $\beta$ & $\mathbf{H}$ & $\mu_{1}$ & $\mu_{2}$ & $\mu_{3}$ & $\mu_{4}$ & $\mu_{5}$ \\
\hline 1. $\mathrm{A} \rightarrow \beta_{1}+\beta$ & -0.001 & - & 0.301 & 0.062 & 0.030 & 0.048 & 0.044 & 0.046 & 0.027 & 0.029 \\
\hline $\mathrm{A} \rightarrow \mu_{2}+\mu_{4}$ & -0.002 & - & 0.129 & 0.243 & 0.123 & 0.1 & 1 & 0.1 & 6 & 0.121 \\
\hline 3. $\mathrm{A}+\mathrm{R} \rightarrow \mu_{2}+\mu_{\mathrm{s}}$ & -0.004 & - & 0.190 & 0.357 & 0.491 & 0.288 & 0.267 & 0.278 & 0.376 & 0.487 \\
\hline 4. $\mu_{2}+\mu_{5} \rightarrow \mathrm{A}+\mathrm{R}$ & - & - & -0.012 & -0.031 & -0.045 & -0.021 & -0.017 & -0.019 & -0.034 & 0.045 \\
\hline 5. $\beta_{1}+\mathrm{A} \rightarrow \mu_{2}+\beta_{1} \mathbf{H}$ & - & $-\cdot$ & -0.894 & 0.010 & 0.011 & 0.015 & 0.016 & 0.016 & 0.010 & 0.011 \\
\hline 6. $\beta+\mathbf{A} \rightarrow \mu_{1}+\beta \mathbf{H}$ & - & - & 0.153 & -0.024 & -0.002 & 0.207 & -0.003 & -0.005 & -0.002 & -0.002 \\
\hline 7. $\beta+\mathrm{A} \rightarrow \mu_{2}+\beta \mathrm{H}$ & - & - & -0.150 & -0.768 & 0.004 & -0.203 & 0.006 & -0.102 & 0.004 & 0.004 \\
\hline 8. $\beta+\mathbf{A} \rightarrow \mu_{3}+\beta \mathbf{H}$ & - & - & - & -0.201 & - & - & - & 0.111 & - & - \\
\hline 9. $\mathbf{H}+\mathbf{A} \rightarrow \mu_{1}+\mathbf{H}_{2}$ & - & - & - & - & -0.001 & - & - & - & - & - \\
\hline 10. $\mathbf{H}+\mathbf{A} \rightarrow \mu_{2}+\mathrm{H}_{2}$ & - & - & - & $\cdots$ & -0.022 & - & - & - & - & - \\
\hline 11. $\mathbf{H}+\mathbf{A} \rightarrow \mu_{3}+\mathrm{H}_{2}$ & - & - & - & - & -0.010 & - & - & - & - & 一. \\
\hline 12. $\mu_{5}+\mathbf{A} \rightarrow \mu_{4}+\mathbf{R}$ & - & - & 0.011 & 0.031 & -0.939 & 0.020 & 0.016 & 0.018 & 0.034 & -0.939 \\
\hline 13. $\mu_{2}+\mathrm{A} \rightarrow \mu_{4}+\mathbf{I}_{2}$ & 0.001 & - & 0.028 & 0.145 & 0.001 & 0.038 & -0.001 & 0.019 & 0.162 & - \\
\hline 14. $\mu_{2}+\mathbf{R} \rightarrow \mu_{5}+I_{2}$ & -0.003 & - & 0.077 & 0.417 & 0.686 & 0.100 & -0.015 & 0.045 & 0.467 & 0.683 \\
\hline 15. $\mu_{2}+\mathrm{A} \rightarrow \mu_{1}+\mathrm{A}$ & - & - & 0.279 & -0.003 & -0.003 & 0.386 & -0.005 & -0.003 & -0.003 & -0.003 \\
\hline 16. $\mu_{2}+\mathbf{A} \rightarrow \mu_{3}+\mathbf{A}$ & 0.001 & - & 0.070 & -0.001 & -0.003 & 0.098 & -0.002 & 0.248 & - & -0.002 \\
\hline 17. $\mu_{3}+\mathrm{A} \rightarrow \mu_{1}+\mathrm{A}$ & - & -- & 0.081 & -0.001 & -0.001 & 0.111 & -0.001 & -0.009 & -0.001 & -0.001 \\
\hline 18. $\mu_{3}+\mathrm{A} \rightarrow \mu_{2}+\mathrm{A}$ & 0.001 & - & -0.080 & 0.001 & - & -0.109 & 0.003 & -0.282 & 0.003 & 0.001 \\
\hline 19. $\mu_{1} \rightarrow \beta_{1}+Q_{1}$ & - & - & 0.034 & & - & -0.953 & -0.001 & -0.004 & - & - \\
\hline 20. $\mu_{2} \rightarrow \beta+Q_{2}$ & - & - & 0.014 & 0.074 & - & 0.019 & -0.001 & 0.010 & -0.001 & - \\
\hline 21. $\mu_{3} \rightarrow \beta+Q_{3}$ & - & - & - & 0.001 & - & - & - & -0.001 & - & - \\
\hline$\beta+Q_{4}+\mathbf{R}$ & - & - & - & - & - & - & - & - & -1.000 & - \\
\hline 23. $\mu_{5} \rightarrow \mathbf{R}+\mathbf{H}$ & - & - & ..- & - & 0.985 & - & - & - & - & -0.015 \\
\hline 24. $\mathrm{A}+\mathrm{H} \rightarrow \mu_{4}$ & - & - & - & 0.001 & -0.491 & - & - & - & 0.001 & -0.007 \\
\hline 25. $\mathbf{R}$ & - & - & - & - & -0.477 & 一 & - & - & - & 0,007 \\
\hline 26. $\beta_{1}+\beta_{1} \rightarrow \beta_{1} \beta_{1}$ & - & - & -0.006 & - & - & -- & - & - & - & \\
\hline 27. $\beta_{1}+\mu_{2} \rightarrow \beta_{1} \mu_{2}$ & -. & - & -0.094 & -0.010 & -0.010 & -0.014 & -0.016 & 0.015 & -0.010 & -0.0 \\
\hline 28. $\beta+\mu$ & - & - & -0.0 & -0.007 & -0.002 & -0.004 & -0.004 & -0.004 & -0.002 & -0.002 \\
\hline 29. $\mu_{2}+\mu_{2} \rightarrow \mu_{2} \mu_{2}$ & & - & -0.26 & -0.289 & -0.309 & -0.416 & -0.466 & -0.439 & -0.286 & -0.307 \\
\hline 30. $\mu_{2}+\mu_{3} \rightarrow$ Term & - & - & -0.0 & -0.002 & -0.002 & -0.004 & -0.003 & -0.006 & -0.002 & -0.002 \\
\hline 31. $\mu_{3} \rightarrow \mu_{2}$ & - & - & -0.192 & 0.003 & 0.004 & -0.265 & 0.006 & -0.679 & 0.004 & 0.004 \\
\hline 32. $\mu_{3} \rightarrow \mu_{\mathrm{i}}$ & - & - & 0.1 & -0.002 & -0.002 & 0.268 & -0.004 & -0.022 & -0.002 & -0.002 \\
\hline 33. $\mu_{1} \rightarrow \mu_{3}$ & - & - & -0.034 & - & - & -0.047 & 0.001 & 0.004 & - & - \\
\hline 34. $\mu_{2} \rightarrow \mu_{3}$ & - & - & 0.171 & -0.003 & -0.003 & 0.236 & -0.005 & 0.605 & -0.003 & -0.003 \\
\hline 35. $\beta_{1} \beta_{1} \rightarrow \beta_{1}+\beta_{1}$ & 一 & - & 0.005 & - & - & - & -- & & - & $\overline{-10}$ \\
\hline $\begin{array}{l}\text { 36. } \beta_{1} \mu_{2} \rightarrow \mu_{2}+\beta_{1} \\
\text { 37. } \mu_{2} \mu_{2} \rightarrow \mu_{2}+\mu_{2}\end{array}$ & $\overline{0.002}$ & 二 & $\begin{array}{l}0.094 \\
0.263\end{array}$ & $\begin{array}{l}0.009 \\
0.288\end{array}$ & $\begin{array}{l}0.010 \\
0.308\end{array}$ & 0.013 & 0.055 & 0.014 & $\begin{array}{l}0.009 \\
0.285\end{array}$ & $\begin{array}{l}0.010 \\
0.306\end{array}$ \\
\hline & & & $0.20 \mathrm{~s}$ & U. $20 x$ & 30 & & 0.46 & 0.438 & 0.285 & \\
\hline
\end{tabular}

apparent autocatalytic kinetics observed for DDP pyrolysis.

(2) Radical hydrogen transfer reactions were required to describe DDP pyrolysis fully. These reactions were especially significant at high DDP concentrations. The dominant RHT steps that engender hydrogenolysis in DDP neat pyrolysis involve $\alpha$-DDP radicals and non-ipso alkylhydropyrenyl radicals as donors. RRD steps are most important at very low conversions.

(3) A sensitivity analysis revealed that initiation events and the reactions of $\alpha$-DDP radicals most strongly influenced the product selectivities and the kinetics of DDP disappearance.

Acknowledgements-This work was supported, in part, by the donors of the Petroleum Research Fund, administered by the American Chemical Society.

\section{REFERENCES}

Allara, D. L. and Shaw, R., 1980, A compilation of kinetic parameters for the thermal degradation of $n$-alkane molecules. J. Phys. Chem. Ref. Data 9, 523-559.

Benson, S. W., 1976, Thermochemical Kinetics, 2nd Edition. Wiley, New York.
Billmers, R., Brown, R. L. and Stein, S. E., 1989, Hydrogen transfer between 9,10-dihydrophenathrene and anthracene. Int. J. chem. Kinet. 31, 375-389.

Billmers, R., Griffith, L. L. and Stein, S. E., 1986, Hydrogen transfer between anthracene structures. $J$. phys, Chem. 90, 517-523.

Blouri, B., Hamdan, F. and Herault, D., 1985, Mild cracking of high-molecular-weight hydrocarbons. Ind. Engng Chem. Proc. Des. Dev. 34, 30-37.

Boudart, M., 1968, Kinetics of Chemical Processes. PrenticeHall, Englewood Cliffs, NJ.

Braun, W., Herron, J. T. and Kahanen, D. K., 1988, A computcr program for modeling complex chemical reaction systems. Int. J. chem. Kinet. 30, 51-62.

Church, D. F. and Gleicher, G. J., 1976, Addition of vinylphenol to polycyclic vinylarenes. J. Org. Chem. 41, 2327-2331.

Dobe, S., Berces, T., Reti, F. and Marta, F., 1987, Isomerization of $n$-hexyl and $s$-octyl radicals by 1,5 and 1,4 intramolecular hydrogen atom transfer reactions. Int. $J$. chem. Kinet. 19, 895-921.

Edelson, D. and Allara, D. L., 1980, A computational analysis of the alkane pyrolysis mechanism: sensitivity analysis of individual reaction steps. Int. J. chem. Kinet. 12, 605-621.

Freund, H., Matturro, M. G., Olmsted, W. N., Reynolds, R. P. and Upton, T. H., 1991, Anomalous side chain cleavage in alkylaromatic pyrolysis. Energy Fuels 5 , $840-846$.

Freund, H. and Olmsted, W. N., 1989, Detailed kinetic 
coefficients for DDP neat pyrolysis

\begin{tabular}{|c|c|c|c|c|c|c|c|c|c|c|c|}
\hline $\mathbf{Q}_{1}$ & $\mathbf{Q}_{2}$ & $\mathbf{Q}_{3}$ & $\mathbf{Q}_{4}$ & $\mathbf{I}_{2}$ & Term & $\mu_{2} \mu_{2}$ & $\beta_{1} \mu_{2}$ & $\beta_{1} \beta_{1}$ & $\mathbf{H}_{2}$ & $\beta \mathbf{H}$ & $\beta_{1} \mathbf{H}$ \\
\hline 0 & 2 & 6 & 022 & 042 & 8 & 7 & .347 & 0.657 & 0.024 & 6 & 67 \\
\hline & & & & & & & & & & & \\
\hline & & & & & & & & & & & \\
\hline 4 & 1 & 0 & 0 & 0.0 & -0.030 & -0.0 & -0.0 & -0 & 0. & & \\
\hline 4 & & & & & & & -0. & -1. & & & \\
\hline 4 & 3 & 0. & 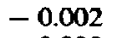 & 0. & 0 & 0. & 0. & 0. & 0. & 2 & \\
\hline & 0.005 & & 0.00 & 0.0 & 7 & & -0.145 & 0.30 & 0.00 & & 0.154 \\
\hline & & & - & - & 0.0 & 0.001 & $\cdots$ & - & - & 0.001 & - \\
\hline - & - & - & - & - & $\cdots$ & - & - & - & & - & - \\
\hline.$- \cdot$ & - & - & - & - & - & - & $\longrightarrow$ & - & & - & - \\
\hline- & - & - & - & - & - & - & - & - & & - & - \\
\hline 0.0 & 001 & 0.01 & 0.02 & 0.01 & 0.03 & 0.03 & 0.02 & 0.018 & 0.1 & 0 & 0.007 \\
\hline & -0 & & & & & -0 & & & - & & \\
\hline & 9 & & 0.4 & & 0 & -0. & & & 0.5 & & \\
\hline & $-0,005$ & 0 & 0.0 & 0. & & & & & 33 & -0. & \\
\hline & 2 & & - & 0.0 & 0 & -0. & & & & - & 0.061 \\
\hline & 1 & 0 & 0.00 & -0. & 0. & -0. & & & -0.0 & -0.00 & \\
\hline 0 & & C & 0.002 & 0.0 & -0 & 0.0 & -0. & -0. & 0.001 & 0.0 & 70 \\
\hline & -0. & 0 & - & -0.0 & 0. & -0. & & & - & - & \\
\hline 0.0 & 1.00 & & 一 & - & 0.038 & -0.001 & 0.013 & 0.027 & - & & 0.012 \\
\hline 一 & 一 & 0.5 & $\cdots$ & - & - & - & - & - & - & 0.001 & - \\
\hline- & - & - & - & 一 & - & - & - & & & & \\
\hline - & - & - & $-\ldots$ & - & - & - & - & - & 0 & - & - \\
\hline - & 一 & - & 0.00 & 一 & - & - & - & - & -0 & - & - \\
\hline- & - & - & --- & - & - & - & - & - & -0.476 & - & - \\
\hline- & - & - & - & - & -0.001 & -0.00 & 0.00 & 0.98 & - & $\cdots$ & -0.007 \\
\hline & 0.01 & 0.01 & 0.00 & 0.01 & -0.028 & -0.0 & & -0.2 & -0.009 & -0.0 & 28 \\
\hline & 0.002 & -0.00 & V.w & -0.002 & 0.5 & -0.0 & -0.006 & -0.0 & -0 & - & 0001 \\
\hline & -0.474 & -0.437 & -0.250 & -0.473 & -0.821 & 0.0 & -0.728 & -0.4 & -0.273 & -0.2 & .206 \\
\hline & -0.002 & -0.004 & -0.001 & -0.002 & 0.479 & -0.007 & -0.006 & -0.004 & -0.001 & -0.0 & -0.001 \\
\hline & & -0.68 & 0.00 & 0.0 & -0.323 & 0.012 & -0.185 & -0.366 & 0.003 & 0.0 & -0.170 \\
\hline & -0.003 & -0.022 & -0.00 & 0.003 & -0.015 & 0.007 & & 0.368 & 0.002 & -0.002 & 0.171 \\
\hline-0. & & & - & & 0.003 & 0.001 & -0.033 & -0.065 & - & - & -0.031 \\
\hline & 0.004 & 0.590 & 0.00 & 0.004 & 0.282 & -0.010 & & 0.321 & 0.002 & 0.002 & 0.147 \\
\hline & & - & & & & - & & 0.606 & - & - & 0.004 \\
\hline & & & & & & 0 & 0.8 & & & & \\
\hline 0.400 & 0.468 & 0.432 & 0.247 & 0.468 & 0.814 & -0.068 & 0.725 & 0.477 & 0.270 & 0.248 & 0.203 \\
\hline
\end{tabular}

modeling of butylbenzene pyrolysis. Int. J. chem. Kinet. 21, $561-574$.

Klein, M. T. and Virk, P. S., 1983, Model pathways in lignin thermolysis 1. Phenethyl phenyl ether. Ind. Engng Chem. Fundam. 22, 35-45.

Malhotra, R. and McMillen, D. F., 1990, A mechanistic numerical model for coal liquefaction involving hydrogenolysis of strong bonds, rationalization of interactive effeets of solvent aromaticity and hydrogen pressure. Energy Fuels 4, 184-193.

McMillen, D. F., Malhotra, R., Chang, S. I., Olgier, W. C, Nigenda, E. and Fleming, R. H., 1987, Mechanisms of hydrogen transfer and bond scission of strongly bonded coal structures in donor-solvent systems. Fuel 66, 1611-1620.

McMillen, D. F., Malhotra, R. and Tse, D. S., 1991, Interactive effects between solvent components: possible chemial origin of synergy in liquefaction and coprocessing. Eneray Fuels 5, 179-187.

McMillen, D. F., Manion, J. A. and Malhotra, R., 1992, Biaryl formation as a source of hydrogen during pyrolysis of resid structural elements. Prepr. Am. Chem. Soc., Div. Fuel Chem. 37, 1636-1642.

Mushrush, G. W. and Hazlett, R. N., 1984, Pyrolysis of organic compounds containing long unbranched alkyl groups. Ind. Engng Chem. Fundam. 33, 288-294.

Poutsma, M. L., 1990, Free-radical thermolysis and hydrogenolysis of model hydrocarbons relevant to processing of coal. Energy Fuels 4, 113-131.
Poutsma, M. L. and Dyer, C. W., 1982, Thermolysis of model compounds for coal 3. Radical chain decomposition of 1 , 3 diphenylpropane and 1, 4 diphenylbutane. J. Org. Chem. 47, 4903-4914.

Savage, P. E., Jacobs, G. E. and Javanmardian, M., 1989, Autocatalysis and aryl-alkyl bond cleavage in 1-dodecylpyrene pyrolysis. Ind. Engng Chem. Res. 38, 645-652.

Savage, P. E. and Klein, M. T., 1987a, Asphaltene reaction pathways. 2. Pyrolysis of $n$-pentadecylbenzene. Ind. Engng Chem. Res. 36, 488-494.

Savage, P. E. and Klein, M. T., 1987b, Discrimination between molecular and free-radical models of 1-phenyldodecane pyrolysis. Ind. Engng Chem. Res. 36, 374-376.

Savage, P. E. and Klein, M. T., 1989, Kinetics of coupled reactions: lumping pentadecylbenzene pyrolysis into three parallel chains. Chem. Engng Sci. 44, 985-991.

Smith, C. M., 1992, Reactions of polycyclic alkylaromatics: pathways, kinetics, and mechanisms. Ph.D. Dissertation, University of Michigan.

Smith, C. M. and Savage, P. E., 1991 a, Reactions of polycyclic alkylaromatics: 1. Pathways, kinetics, and mechanisms for 1-dodecylpyrene pyrolysis. Ind. Engng Chem. Res. 30, $331-339$.

Smith, C. M. and Savage, P. E., 1991b, Reactions of polycyclic alkylaromatics: 2 . Pyrolysis of $\alpha-\omega$-diarylpropanes. Energy Fuels 5, 146-155.

Smith, C. M. and Savage, P. E., 1991c, Reactions of polycyclic alkylaromatics: structure and reactivity. A.I.Ch.E. $J$. 37, 1613-1624. 
Smith, C. M. and Savage, P. E., 1992, Reactions of polycyclic alkylaromatics: 4. Hydrogenolysis mechanisms in 1-alkylpyrene pyrolysis. Energy Fuels 6, 195-202.

Smith, C. M. and Savage, P. E., 1993, Reactions of polycyclic alkylaromatics: 5. Pyrolysis of methylanthracenes. A.I.Ch.E. J. 39, 1355-1368.

Stein, S. E. and Brown, R. L., 1991, Prediction of carbonhydrogen bond dissociation energies for polycyclic aromatic hydrocarbons of arbitrary size. J. Am. Chem. Soc. $113,787-793$.

Tsang, W., 1992, Kinetic stability of unsaturated organics at high temperatures. Prepr. Pap. Am. Chem. Soc., Div. Fuel Chem. 37, 367-374.

Turanyi, T., $1990 \mathrm{a}$, Sensitivity analysis of complex kinetic systems. Tools and applications. I. Math. Chem. S, 203-248.
Turanyi, T., 1990b, KINAL: a program package for kinetic analysis of reaction mechanisms. Comput. Chem. 14, 253-254,

Vernon, L. W., 1980, Free radical chemistry of coal liquefaction: role of molecular hydrogen. Fuel 59, 102-107.

Virk, P. S. and Vlastnik, V. J., 1992, Pathways for thermolysis of 9,10-dimethylanthracene. Prepr. Pap. Am. Chem. Soc, Div. Fuel Chem. 37, 947-953.

Walker, J. A. and Tsang, W., 1990, Single-pulse shock tube studies on the thermal decomposition of $n$-butyl phenyl ether, $n$-pentylbenzene, and phenotole and the heat of formation of phenoxy and benzyl radicals. J. phys. Chem. 94, 3324-3327. 